\title{
Biological Control of Meloidogyne incognita by Trichoderma harzianum
}

\author{
Kurulkar Uday ${ }^{*}$, Bhabesh Bhagawati ${ }^{1}$ and Pranjal Pratim Neog $^{2}$ \\ ${ }^{I}$ Department of Nematology, Assam Agricultural University, Jorhat, Assam, India \\ ${ }^{2}$ B.N.C.A, Biswanath Chariali, Assam Agricultural University, Jorhat, Assam, India \\ *Corresponding author
}

\begin{tabular}{|l|}
\hline K e y w or d s \\
$\begin{array}{l}\text { M. incognita, } \\
\text { Eggmass, Juvenile, } \\
\text { Trichoderma } \\
\text { harzianum, Okra }\end{array}$ \\
\hline Article Info \\
\hline $\begin{array}{l}\text { Accepted: } \\
\text { 18 January } 2019 \\
\text { Available Online: } \\
\text { 10 February } 2019\end{array}$ \\
\hline
\end{tabular}

\section{A B S T R A C T}

Trichoderma harzianum parasitism on Meloidogyne incognita eggs and juveniles was examined in-vitro under Assam condition. M. incognita egg masses, their derived eggs and second-stage juveniles $\left(\mathrm{J}_{2}\right)$ were parasitized by $T$. harzianum. The conidia of the $T$. harzianum were found inside of the eggs and attached to the $\mathrm{J}_{2} \mathrm{~s}$ with the gelatinous matrix. The eggs were penetrated and parasitized by the hyphae of $T$. harzianum, while eggs containing juveniles were also parasitised by $T$. harzianum. Further, isolate $T$. harzainum was used for to know the bio-efficacy against $M$. incognita infected on okra under pot condition. For this T. harzianum was applied either as a seed treatment and/or soil application or both. Carbosulfan as a seed treatment and carbofuran as soil application was applied as chemical checks both either singly or in combination. The results showed that either T. harzianum or the chemicals (Carbofuran and Carbosulfan) when applied together as a seed treatment and soil application, improved plant growth parameters of okra and reduced the nematode multiplication as compared to when they were applied either as a seed treatment or soil application. Application of chemicals either as a seed treatment or soil application emerged as the most effective treatment as compared to the T. harzianum. However, in respect of $T$. harzianum when applied together as a seed treatment and soil application showed significantly better results in an improving the plant growth parameters and reduction in the nematode multiplication as compared to the treatments with carbosulfan as a seed treatment and carbofuran as soil application alone.

\section{Introduction}

Root-knot nematodes Meloidogyne spp. is one of the major pathogens of vegetable crops in Assam (Anon., 2011) and it caused five per cent of global crop loss (Hussey and Janssen, 2002). These microscopic species may not cause appreciable crop loss or symptom development as other pests and pathogens do and regarded as the hidden enemy of the farmers. Meloidogyne spp exhibit obligate type of relationship with host and produced the giant cell as feeding cell and it act as a metabolic sink which diverts the nutrient towards them (Davis et al., 2004) as a result they produced galls on the roots. However, root-knot nematode laid their eggs in a gelatinous matrix and collectively known as egg mass. Such egg masses are exposed to the rhizosphere. Further, these egg masses are heavily colonized by microorganisms which are present in the rhizosphere and become an important factor in finding the nematode antagonists (Kok et al., 2001). Kok et al., 
2001 reported that bacteria, fungi, protozoa, mites, etc. are feed on the egg mass of rootknot nematode but the utilization of fungi are unique natural enemies for the management of plant parasitic nematodes (Mark et al., 2010). The fungi which feed on the nematodes are called as nematophagous fungi. Such fungi are obligate parasites of nematodes and some are opportunistic fungi which are mostly saprophytic in nature but when nematode will come in contact with them suddenly they trigger their nematocidal activity (Jansson and Nordbring-Hertz, 1988) like predation, parasitism etc. They can be categorized into four major groups: nematode-trapping fungi, endoparasitic fungi, egg-parasitic fungi, and toxin-producing fungi (Zhang and Hyde, 2014).

The activity of egg-parasitic fungi is essential because they mostly prefer the adults, eggs, and juveniles so it helps in the reducing the nematode inoculums while in the nematodetrapping fungi the juveniles of nematode some time escape from the traps and such trapping fungi either showed a poor competitive saprophytes or are susceptible to antagonism from other soil fungi (Mankau, 1962). Lysek (1963) for the first time observed invasion and destruction of nematode eggs by Fusarium spp. and Cephalosporium spp. and later so many egg parasitic fungi like Acremonium bacilosporum, Helicoon farinosum, Mortierella nana, Paecilomyces lilacinus, Verticiluum chlamydosporium and $V$. bulbillosum (Lysek, 1966), P lilacinus (Pau et al., 2012), T. atroviride and T. asperellum (Sharon et al., 2007), P. chlamydosporia, P. lilacinus and A. strictum, $F$. oxysporium, $T$. harzianum, $T$. viride, $F$. chlamydosporium, $C$. oxysporum and $C$. aubense (Singh and Mathur, 2010) and A. implicatum (Yao et al., 2015) were reported from Meloidogyne spp. However, Trichoderma spp. are more rhizospheric competent than other fungi and showed nematicidal activity like (i) production of mycotoxins that immobilized $\mathrm{J}_{2}$, (ii) direct antagonism on the pathogen like nematode (Shoresh et al., 2010; Hermosa et al., 2012; Brotman et al., 2013) and pathogenic fungi by the action of antibiosis, competition, enzymatic hydrolysis, parasitism and systemic induced resistance (Chet et al., 1997; Harman et al., 2004) and (ii) It showed root colonization and directly influence the growth of the plants, either reduced abiotic stresses or increase the nutrient uptake (Harman et al., 2004). The use of native biocontrol agents for the controlling of exotic plants appears to be beneficial because they are easy to apply and showed less environmental risk (Cofrancesco, 2000). Hence the present study was undertaking to determine the biocontrol activity of $T$. harzianum against $M$. incognita with the following two objectives (i) mycoparasitism of $T$. harzianum on $M$. incognita eggs and (ii) bio-efficacy of $T$. harzianum against $M$. incognita on okra under pot condition.

\section{Materials and Methods}

\section{Collection of sample}

Trichoderma harzianum isolated from the egg masses of $M$ incognita and identified from the Department of Plant Pathology, AAU, Jorhat, Assam.

\section{Collection of egg masses}

Egg masses were collected from the galled root from each sample. Root pieces with galls were mixed thoroughly, washed in running tap water for 5 minute to get rid of soil and placed under a stereomicroscope. Egg masses were handpicked from the galled roots with help of a sterilized forceps. The egg masses thus collected were kept in sterilized cavity block containing $2 \mathrm{ml}$ sterile distilled water. 


\section{Surface sterilization of egg masses}

The collected egg masses were surface sterilized in 0.4 percent sodium hypochlorite (NaOCl) for two minutes (Singh and Mathur, 2010). Egg masses were washed thoroughly with sterile distilled water until the traces of $\mathrm{NaOCl}$ was removed and placed in cavity block for further use.

\section{Preparation of media}

The ingredients used for preparation of potato dextrose agar (PDA) are peeled potato (200 $\mathrm{gm})$, dextrose (20 gm), agar-agar (20 gm) and distilled water $(1000 \mathrm{ml})$. Peeled potatoes were boiled in $500 \mathrm{ml}$ water. Potato extract was separated by using double layer muslin cloth and measured amount of dextrose was added to the extract. In another flask, remaining $500 \mathrm{ml}$ distilled water was taken, required amount of agar-agar was added and molted by boiling. The molten agar- agar was strained through double layer muslin cloth and mixed with potato dextrose extract solution. The volume was made upto $1000 \mathrm{ml}$ by adding distilled water. $\mathrm{P}^{\mathrm{H}}$ was measured and maintained at 7.0 by $\mathrm{NaOH}$. The medium was poured into culture tubes and conical flask plugged by non-absorbent cotton and then sterilized in autoclave at $121^{\circ} \mathrm{C}$ for 20 minutes.

\section{Mycoparasitism of $T$. harzianum on $M$. incognita eggs}

Culture of fungal specie were inoculated to the center of a petriplate containing PDA medium amended with streptomycin as antibiotic@1 ml/L at full growth,4 egg masses were placed on the petriplate and incubated at $25 \pm 2^{\circ} \mathrm{C}$ for 7 days. After 7 days of incubation, the portion of the fungal growth containing egg masses were collected on Hawkshely counting dish and stained with lactophenol cotton blue. The eggs were observed under compound microscope (60x objective lens) for the presences of morphological structures (hyphae, conidiophores, conidia, chlamydospores) of $T$. harzianum were noted during microscopic observations.

Bio-efficacy of $T$. harzainum against $M$. incognita on okra under pot conditions

\section{Experimental site}

The experiment was conducted in the net house of the Department of Nematology, AAU Jorhat during 2015-2016.

\section{Mass culture of $T$. harzianum for soil application}

For mass culture of isolated T. harzianum, $1 \mathrm{~kg}$ vermicompost was put in to polypropylene bags plugged with nonabsorbent cotton and autoclaved at $121{ }^{\circ} \mathrm{C}$ for 30 minutes. Each bag containing the sterilized medium was inoculated with $T$. harzianum under aseptic conditions and was incubated at $25 \pm 2{ }^{\circ} \mathrm{C}$ for 15 days. After 15 days of incubation the materials were mixed thoroughly and $c f u$ was counted, maintained at $1 \times 10^{7} \mathrm{cfu} / \mathrm{gm}$ and used for application in pots (@5gm/kg soil).

\section{Seed treatment with $T$. harzianum}

Spore suspension of isolated T. harzianum was prepared from 15 day old culture grown in PDA slants. The spores were suspended in sterile distilled water and the concentration was adjusted to $1 \times 10^{7}$ spores $/ \mathrm{ml}$ with the help of a haemocytometer. Carboxy methyl cellulose (CMC) was used as an adhesive for treating okra seeds with $T$. harzianum spore suspension. For preparing 2\% (w/v) adhesive solution, $200 \mathrm{mg}$ of adhesive was added to 10 $\mathrm{ml}$ of antagonist suspension. Now required amount of seeds was taken in a petri plate and 
the antagonist suspension with the adhesive was added drop by drop on the seeds stirring continuously. Addition of spore suspension was stopped when all the seeds got smeared with the spore suspension. After treating, the seeds were dried in shade for 6 hours and used for sowing.

\section{Seed treatment with chemicals}

Seeds were treated with Carbosulfan 25STD @ 3\% and gum arabic was used as sticker. The weighed quantity of seed was mixed properly to form uniform coating over the seeds. Treated seeds were dried in shade and were sown in pots.

\section{Soil application of chemical}

Carbofuran@1 kg a.i/ha were applied and mixed thoroughly with the soil before sowing of the seed in pot.

\section{Source of seeds}

Seeds of okra cv. 'Parvani Kranti highly susceptible to $M$. incognita was obtained from Assam Seed Corporation ltd., Jorhat Branch, Assam.

\section{Sterilization of seeds}

Seeds were washed with clean tap water and were surface sterilized with 0.1 per cent mercuric chloride solution for 1-2 minutes and then washed with sterile water. The wet seeds were then dried in the air.

\section{Collection and sterilization of soil}

Required amount of soil was collected from upland near the nematode culture house, Department of Nematology, Assam Agricultural University, Jorhat. The soil was mixed thoroughly after removing unwanted materials like stones and roots. Then the soil was mixed homogenously with finely dried cow dung and sand in the ratio of $2: 1: 1$, respectively. The soil mixture was put in a gunny bag and sterilized in an autoclave at $121^{\circ} \mathrm{C}$ for half an hour.

\section{Filling up of pots}

Earthen pots with $1 \mathrm{~kg}$ capacity were selected, cleaned and sterilized in sunshine for conducting the experiment on biochemical analysis. Few broken pieces of bricks were placed at the bottom of the pots before filling up with sterilized soil mixture. Proper labeling of each pot was done.

Extraction of $M$. incognita juveniles $\left(\mathbf{J}_{2}\right)$ from eggs

For extraction of juveniles $\left(\mathrm{J}_{2}\right)$, the sterilized eggs collected as described above were placed on a double layer facial tissue paper supported on a course aluminum wire mesh. This was placed over a $10 \mathrm{~cm}$ diameter petriplate filled with required quantity of water at $24-26{ }^{\circ} \mathrm{C}$ in BOD incubator for hatching. Several such assemblies were maintained. The juveniles collected from these were mixed together at the time of inoculation in in-vitro studies. The counting of juveniles in the suspension was made by using Hawkshley counting dish. Five aliquots of $1 \mathrm{ml}$ suspension were counted and their average number was multiplied with total volume of suspension prepared.

\section{Inoculation of root knot nematode $M$. incognita juveniles $\left(\mathbf{J}_{2}\right)$}

Freshly hatched second stages of juveniles $\left(\mathrm{J}_{2}\right)$ of $M$. incognita were inoculated @ $1 \mathrm{~J}_{2} / \mathrm{cc}$ of soil.

\section{Treatment details}

$\mathrm{T}_{1^{-}}$Control, $\mathrm{T}_{2^{-}}$Seed treatment with $T$. harzainum @ $1 \times 10^{7} \mathrm{cfu} / \mathrm{ml}, \quad \mathrm{T}_{3^{-}}$Soil 
application of T. harzainum @ 1x10 cfu/gm at $5 \mathrm{~g} / \mathrm{kg}$ of soil, $\mathrm{T}_{4}$ - Seed treatment with $T$. harzainum@1 @10 cfu/ml + Soil application of T. harzainum @1 1 $10^{7} \mathrm{cfu} / \mathrm{gm}$ at $5 \mathrm{~g} / \mathrm{kg}$ of soil, $\mathrm{T}_{5}-$ Seed treatment with Carbosulfan 25STD @ 3\%, $\mathrm{T}_{6^{-}}$Soil application of Carbofuran @ $1 \mathrm{~kg} a . i / \mathrm{ha}, \mathrm{T}_{7}$ - Seed treatment with Carbosulfan 25STD @ 3\% + Soil application of Carbofuran @ $1 \mathrm{~kg}$ a.i/ha. Further each treatment is replicated four times in completely randomized design.

\section{Observations}

\section{Shoot length (cm)}

The main shoot was measured in centimeter from the ground level up to tip of the longest leaf after 60 days of sowing.

\section{Root length (cm)}

The main root length was measured in centimeter from the ground level up to tip of the longest root after 60 days of sowing.

\section{Fresh shoot and root weight (gm)}

The fresh shoot and root weight per plant was measured in gram after 60 days of sowing. These plants were weighed on the weigh balance at Nematology laboratory.

\section{Dry shoot and root weight (gm)}

For recording dry weights, shoots and roots were separately cut into small pieces and kept in an oven running constantly at $60^{\circ} \mathrm{C}$ at Nematology laboratory. The materials were weighed at every $24 \mathrm{hrs}$ interval until a constant weight was obtained.

\section{Number of galls and egg masses per root system}

The number of galls and egg masses per root system was measured after 60 days of sowing.

\section{Final nematode population}

For recording the final nematode population in soil, $200 \mathrm{cc}$ of soil was collected from each pot separately and processed by modified Cobb's sieving and decanting technique (Christie and Perry, 1951).

\section{Statistical analysis}

The data were analyzed by using WASP Web Agri Stat Package 2.0 version software. Duncan's Multiple Range Test (DMRT) was conducted to determine the significance of treatments.

\section{Results and Discussion}

\section{Mycoparasitsm by isolate T. harzianum on} M. incognita eggs

Root knot nematode laid their eggs in a gelatinous matrix (gm) which is secreted by the six rectal glands of the adult female which covers the eggs (i.e., egg mass) and exposed to the rhizospher by rupturing the roots. The chemical composition of the gelatinous matrix contains fucose and $\mathrm{N}$-acetyl-glucosamine as carbohydrates which protect the eggs from the adverse environmental condition (Sharon and Spiegel, 1993). However, gm acts as a food source for the fungi and when come in contact with it suddenly they trigger the production of lytic enzymes like chitinase, protease and collagenase (Mortan et al., 2004 and Sharon et al., 2007). Such enzymes in combination, destroyed the lipid layer, hydrolyzed the chitin and altered the vitelline layer that causes the physiological and morphological changes in the eggs (Tikhonov et al., 2002 and Khan et al., 2004). Such fungi are able to feed on the inner content of the eggs and proliferated inside of the eggs, when the egg content is finished they produced the resting spores inside or outside of the eggs. In the present study, the egg masses of $M$. incognita 
were directly exposed to the pure culture of $T$. harzianum isolated from the eggmass of $M$. incognita and studied the parasitism of $T$. harzianum on eggs after 7 days of incubation. However, under microscope it observed that T. harzianum grow on the egg mass surface and the hyphae of $T$. harzianum were observed to be tightly attached to the egg surface and penetrated inside of the egg shell (Fig. 1a) as a result they completely fed on the internal contents of the eggs (Fig. 1a) and they formed conidia inside of the eggs. Further, the complete proliferation of $T$. harzianum was observed inside the eggs (Fig. 1b). However, the $T$. harzianum not only prefer the immature eggs but also parasitized to the egg containing juveniles as a result the complete proliferation of hyphae of $T$. harzianum is seen to parasitized the juvenile which emerged from the egg (Fig. 2c). However, it is observed that, the isolate showed a complete morphological alteration of juvenile inside of the egg (Fig. 2d) and inhibited the mature eggs to hatch. Similar type of observations were reported by Saifullah and Thomas, 1996 who reported that T. harzianum was able to grow on the egg surface and penetrated the egg shell. Szabo' et al., (2012) also showed that Trichoderma sp. formed the appresorium like structure and penetrated inside of the eggs and developed into a trophic hyphae inside the eggs of $C$. elegans. Sharon et al., (2007) observed that conidia and hyphae of Trichoderma species were tightly attached to the surfaces of egg and further, they recorded that germinating hyphae of Trichoderma species directly penetrated to the egg masses and not only parasitised to the eggs but also parasitized to the $\mathrm{J}_{2} \mathrm{~s}$ within eggs and thus confirm the result of the present study. In the present investigation it reveals that the fungi, $T$. harzianum directly parasitized to $\mathrm{J}_{2}$ which emerged from the eggs and proliferate inside the $\mathrm{J}_{2}$ of $M$. incognita (Fig. 2). However, similar type of observation also reported by
Sharon et al., (2007) who suggested that gelatinous matrix of egg mass contains fucose (carbohydrate) which attached to the surface coat of $\mathrm{J}_{2} \mathrm{~s}$ during hatching and it can change the binding properties of conidia that contain fucose-binding domains so that gelatinous matrix $-\mathrm{J}_{2} \mathrm{~S}$ are efficiently attached and parasitized by the fungus.

\section{Bio-efficacy of $T$. harzainum against $M$. incognita on okra under pot conditions}

The data on plant growth parameters (Table 1, Fig. 3, 5 and 6) viz., plant height, shoot weight (fresh and dry), root weight (fresh and dry) reveal that all the treatments significantly improved the plant height from that of control. The maximum plant height, shoot weight (fresh and dry), root weight (fresh and dry) were recorded in the treatment $\mathrm{T}_{7}$ i.e seed treatment with Carbosulfan 25STD@3\%+ soil application of Carbofuran @ $1 \mathrm{~kg}$ a.i/ha followed by $\mathrm{T}_{4}$ i.e seed treatment with $T$.

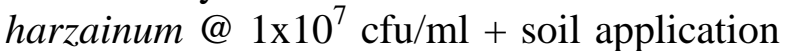
of T. harzainum @1×10 $\mathrm{cfu} / \mathrm{gm}$ at $5 \mathrm{~g} / \mathrm{kg}$ of soil. Among the treatments with bioagents, the treatment $\mathrm{T}_{4}$ was found significantly superior to rest of the treatments. The results showed that $T$. harzianum when applied together as a seed treatment and soil application significantly improved the plant growth parameters as compared to when it was applied either as a seed treatment or soil application. The growth promotion in the treatments receiving Trichoderma spp. are because of it is more rhizospheric competent and have their direct influence on either plant's growth or induction of plant defensive activity against pathogens (Shoresh et al., 2010, Hermosa et al., 2012, Brotman et al., 2013). Naserinasab et al., (2012) observed that application of Trichoderma spp found to improve the plant growth parameters through enzymatic activities in the treated Lycopersicon spp. which ultimately reduced the biotic potentiality of plant-parasitic 
nematode, $M$. incognita. Similarly, Annapurna et al., (2018) reported that soil application of $T$. harzianum induce defencerelated enzymatic activity like peroxidase (PO), polyphenol oxidase (PPO), phenylalanine ammonia lyase (PAL) and total phenol content in tomato against $M$. incognita and as a result improved the plant growth parameters like shoot height, shoot weight, root length, root weight after 15, 30 and 45 days after inoculation and reduced the nematode multiplication on the tomato and in the soil as compared to the untreated control after 30 and 45 days after inoculation. However, the same type modes of action might be posses by the isolated $T$. harzianum against $M$. incognita in the present investigation.

Table.1 Effect of T. harzianum on growth parameters of okra infected by $M$. incognita

\begin{tabular}{|c|c|c|c|c|c|}
\hline Treatments & $\begin{array}{l}\text { Plant height } \\
\text { (cm) }\end{array}$ & $\begin{array}{l}\text { fresh shoot weight } \\
\text { (gm) }\end{array}$ & $\begin{array}{c}\text { Dry shoot weight } \\
\text { (gm) }\end{array}$ & $\begin{array}{l}\text { fresh root weight } \\
\text { (gm) }\end{array}$ & $\begin{array}{c}\text { Dry root weight } \\
(\text { gm) }\end{array}$ \\
\hline $\mathbf{T}_{1}$ & $48.75^{\mathrm{e}}$ & $37.56^{f}$ & $4.27^{\mathrm{g}}$ & $4.28^{\mathrm{e}}$ & $1.42^{\mathrm{g}}$ \\
\hline $\mathbf{T}_{2}$ & $52.90^{\mathrm{d}}$ & $44.25^{\mathrm{d}}$ & $6.46^{\mathrm{e}}$ & $7.63^{d}$ & $2.23^{f}$ \\
\hline $\mathbf{T}_{3}$ & $51.25^{\mathrm{d}}$ & $41.00^{e}$ & $4.76^{f}$ & $7.33^{d}$ & $2.56^{\mathrm{e}}$ \\
\hline $\mathbf{T}_{4}$ & $57.30^{b}$ & $51.99^{\mathrm{b}}$ & $7.89_{b}$ & $7.89^{b}$ & $3.31^{\mathrm{b}}$ \\
\hline $\mathbf{T}_{5}$ & $54.35^{c}$ & $46.50^{d}$ & $7.63^{c}$ & $6.46^{c}$ & $2.60^{d}$ \\
\hline $\mathbf{T}_{6}$ & $53.02^{c}$ & $49.00^{c}$ & $7.33^{d}$ & $6.26^{\mathrm{c}}$ & $2.85^{\mathrm{c}}$ \\
\hline $\mathbf{T}_{7}$ & $60.50^{\mathrm{a}}$ & $55.80^{a}$ & $8.04^{\mathrm{a}}$ & $8.04^{\mathrm{a}}$ & $3.60^{\mathrm{a}}$ \\
\hline S. Ed \pm & 1.15 & 1.31 & 0.05 & 0.22 & 0.05 \\
\hline$p \leq 0.05$ & 2.38 & 2.74 & 0.12 & 0.46 & 0.11 \\
\hline
\end{tabular}

Mean with different letters in the column are significantly different from each other based on Turky HDS test

$\mathbf{T}_{1^{-}}$Control, $\mathbf{T}_{2^{-}}$Seed treatment with T. harzainum @ $1 \times 10^{7} \mathrm{cfu} / \mathrm{ml}, \mathbf{T}_{3^{-}}$Soil application of T. harzainum @ 1x10 ${ }^{7} \mathrm{cfu} / \mathrm{gm}$ at $5 \mathrm{~g} / \mathrm{kg}$ of soil, $\mathbf{T}_{\mathbf{4}^{-}} \mathrm{T} 2+\mathrm{T} 3, \mathbf{T}_{\mathbf{5}^{-}}$Seed treatment with Carbosulfan 25STD @ 3\%, $\mathbf{T}_{\mathbf{6}^{-}}$Soil application Carbofuran @ 1 kg a.i/ha, $\mathbf{T}_{7^{-}}$ $\mathrm{T} 5+\mathrm{T} 6$

Table.2 Effect of T. harzianum on nematode multiplication on okra infected by $M$. incognita

\begin{tabular}{|l|c|c|c|c|}
\hline Treatments & Galls/root system & $\begin{array}{c}\text { Eggmasses/root } \\
\text { system }\end{array}$ & Eggs/eggmass & FNP \\
\hline $\mathbf{T}_{\mathbf{1}}$ & $213.25(14.61)^{\mathrm{a}}$ & $154.50(12.43)^{\mathrm{a}}$ & $275.00(16.57)^{\mathrm{a}}$ & $1514.00(38.90)^{\mathrm{a}}$ \\
\hline $\mathbf{T}_{\mathbf{2}}$ & $108.50(10.44)^{\mathrm{c}}$ & $93.75(9.71)^{\mathrm{b}}$ & $156.00(12.47)^{\mathrm{b}}$ & $783.67(27.98)^{\mathrm{b}}$ \\
\hline $\mathbf{T}_{\mathbf{3}}$ & $127.50(11.31)^{\mathrm{b}}$ & $98.25(9.94)^{\mathrm{b}}$ & $162.75(12.76)^{\mathrm{b}}$ & $866.75(29.39)^{\mathrm{b}}$ \\
\hline $\mathbf{T}_{\mathbf{4}}$ & $97.00(9.87)^{\mathrm{d}}$ & $84.00(9.19)^{\mathrm{c}}$ & $113.75(10.67)^{\mathrm{e}}$ & $533.15(23.07)^{\mathrm{d}}$ \\
\hline $\mathbf{T}_{\mathbf{5}}$ & $85.00(9.27)^{\mathrm{f}}$ & $51.50(7.21)^{\mathrm{e}}$ & $129.00(11.36)^{\mathrm{d}}$ & $600.00(24.43)^{\mathrm{c}}$ \\
\hline $\mathbf{T}_{\mathbf{6}}$ & $91.00(9.56)^{\mathrm{e}}$ & $56.50(7.55)^{\mathrm{d}}$ & $138.75(11.78)^{\mathrm{c}}$ & $650.00(25.47)^{\mathrm{c}}$ \\
\hline $\mathbf{T}_{\mathbf{7}}$ & $56.25(7.54)^{\mathrm{g}}$ & $35.75(6.02)^{\mathrm{f}}$ & $106.50(10.32)^{\mathrm{f}}$ & $400.00(19.97)^{\mathrm{e}}$ \\
\hline $\mathbf{S . ~ E d ~} \mathbf{P}$ & 0.13 & 0.15 & 0.14 & 0.52 \\
\hline $\mathbf{P} \leq \mathbf{0 . 0 5}$ & 0.27 & 0.25 & 0.29 & 1.08 \\
\hline
\end{tabular}

Figure in parenthesis are square root transform value before analysis.

Mean with different letters in the column are significantly different from each other based on Turky HDS test

$\mathbf{T}_{1^{-}}$Control, $\mathbf{T}_{2^{-}}$Seed treatment with T. harzainum @ 1x10 $\mathrm{cfu} / \mathrm{ml}, \mathbf{T}_{3^{-}}$Soil application of T. harzainum @ 1x10 cfu/gm at $5 \mathrm{~g} / \mathrm{kg}$ of soil, $\mathbf{T}_{4^{-}} \mathrm{T} 2+\mathrm{T} 3, \mathbf{T}_{5^{-}}$Seed treatment with Carbosulfan 25STD @ 3\%, $\mathbf{T}_{6^{-}}$- Soil application Carbofuran@1kg a.i/ha, $\mathbf{T}_{7}$ - T5 + T6 
Fig.1 Meloidogyne incognita eggs/juvenile parasitised by Trichoderma harzianum
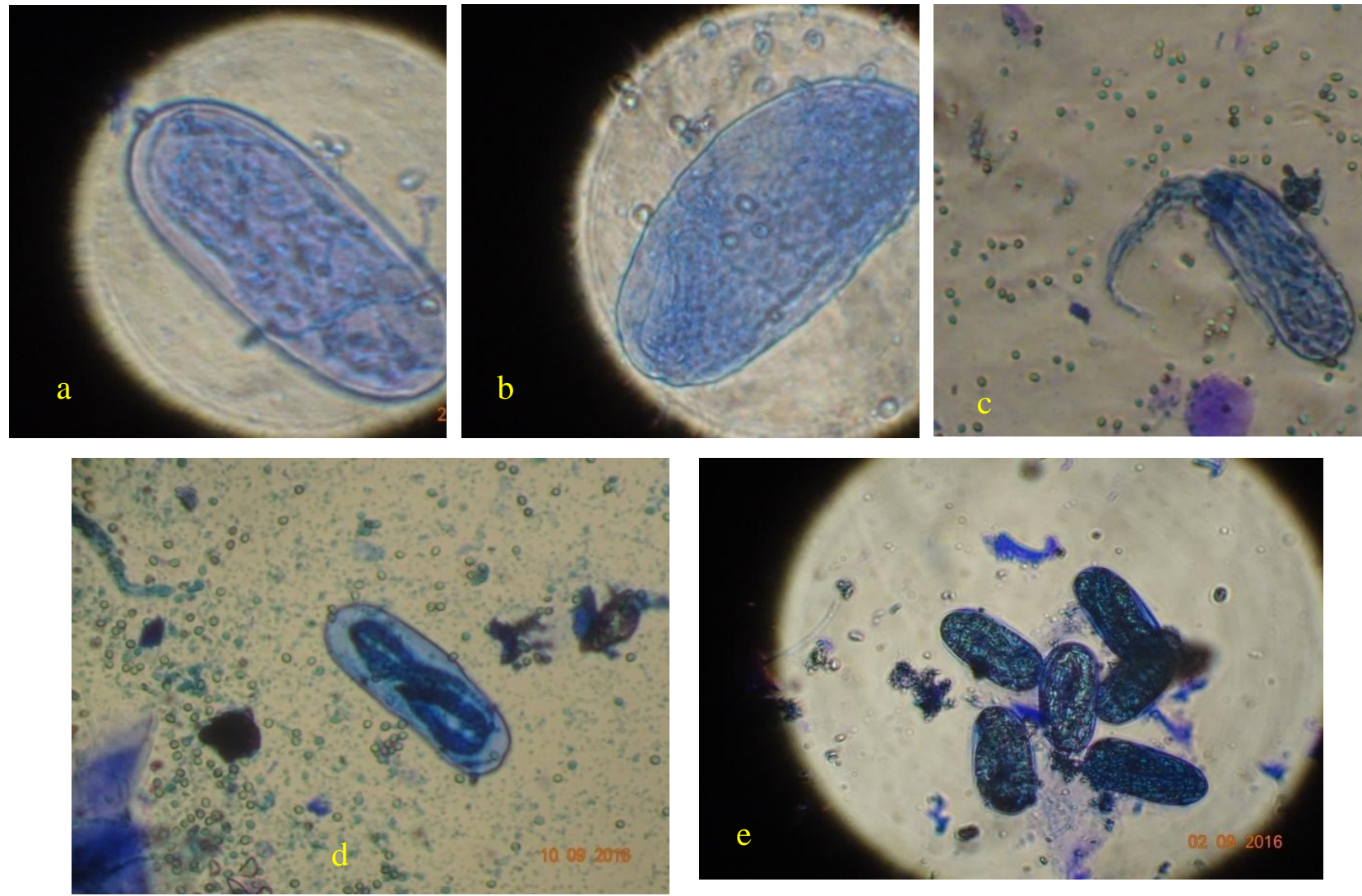

a. Penetration of the egg shell and degradation of egg embryo b. Extensive network of hyphae inside the egg c. Parasitised to $\mathbf{J}_{2}$ emerging from the egg (arrow pointing at $\mathbf{J}_{2}$ ) d. Morphological alteration of juvenile inside the egg e. Unparasitised mature eggs

Fig.2 T. harzianum parasitised to $M$. incognita $\mathrm{J}_{2}$

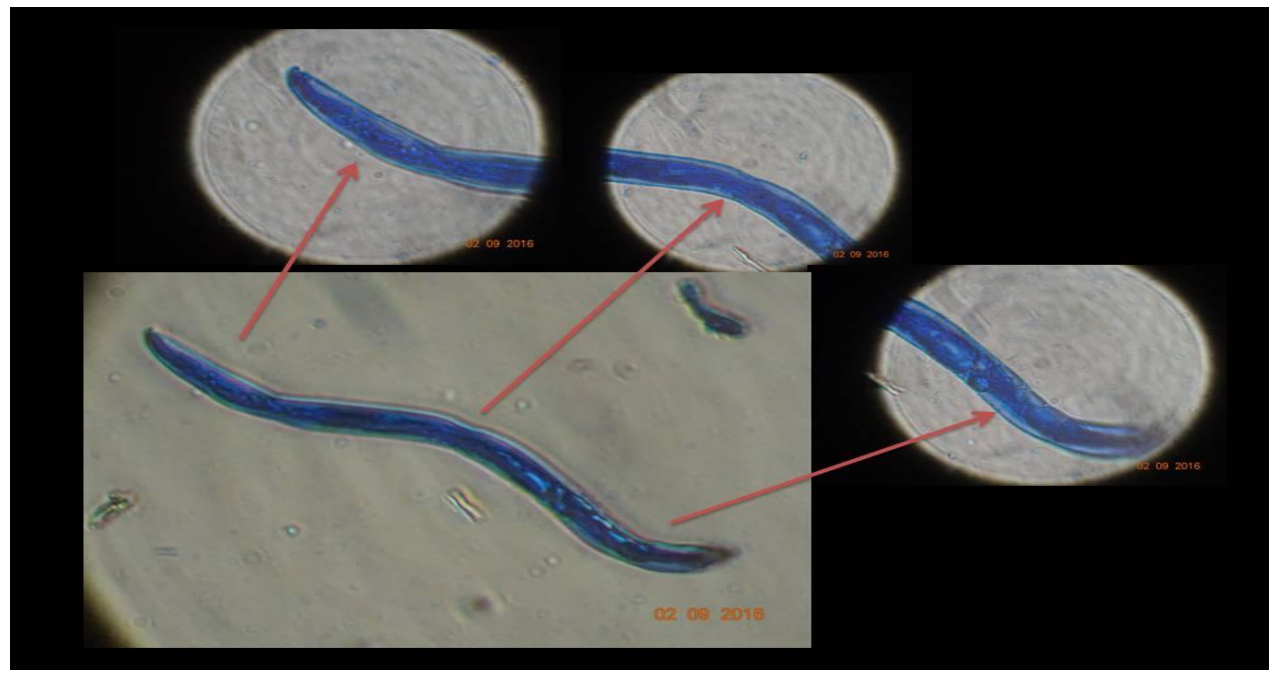

(Arrow indicate extensive network of hyphae inside the $\mathbf{J}_{2}$ ) 
Fig.3 General view of pot experiment

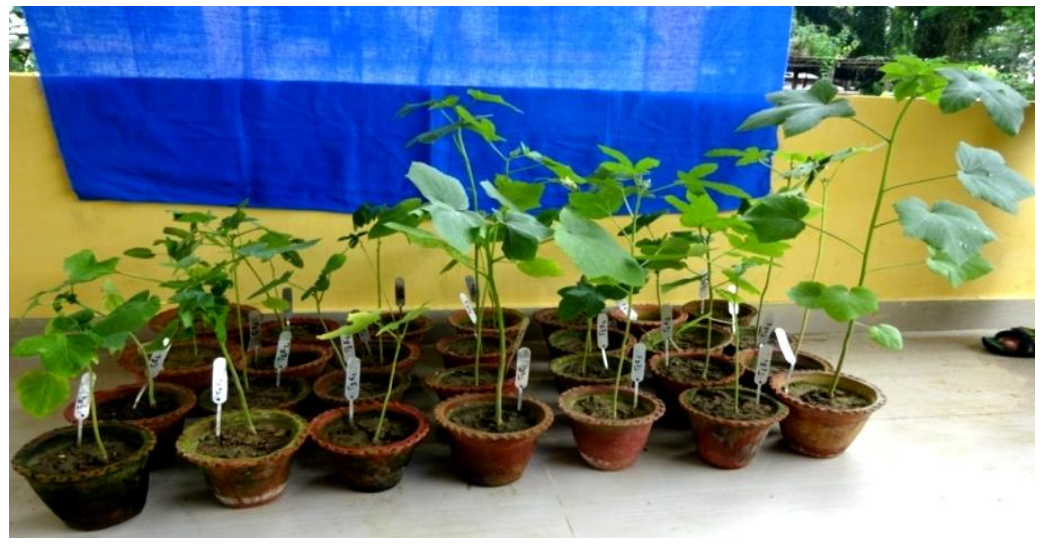

Fig.4 Root galls in different treatments (Th- T. harzianum)

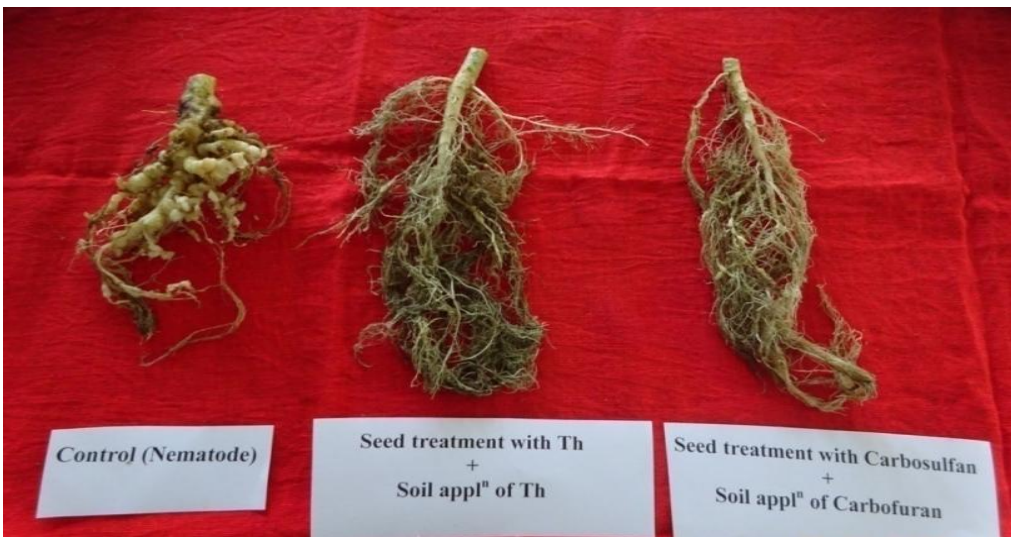

Fig.5 Effect of different treatments on plant height of okra infected by $M$. incognita

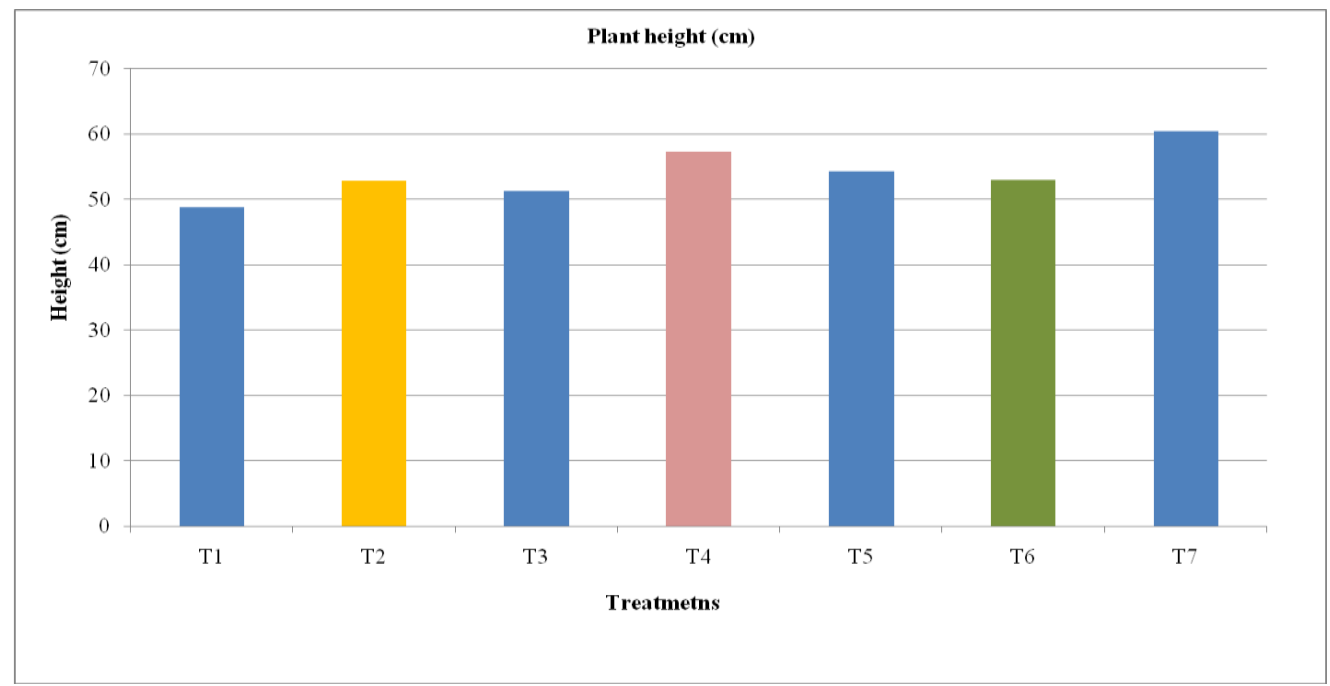


Fig.6 Effect of different treatments on growth parameters of okra infected by M. incognita

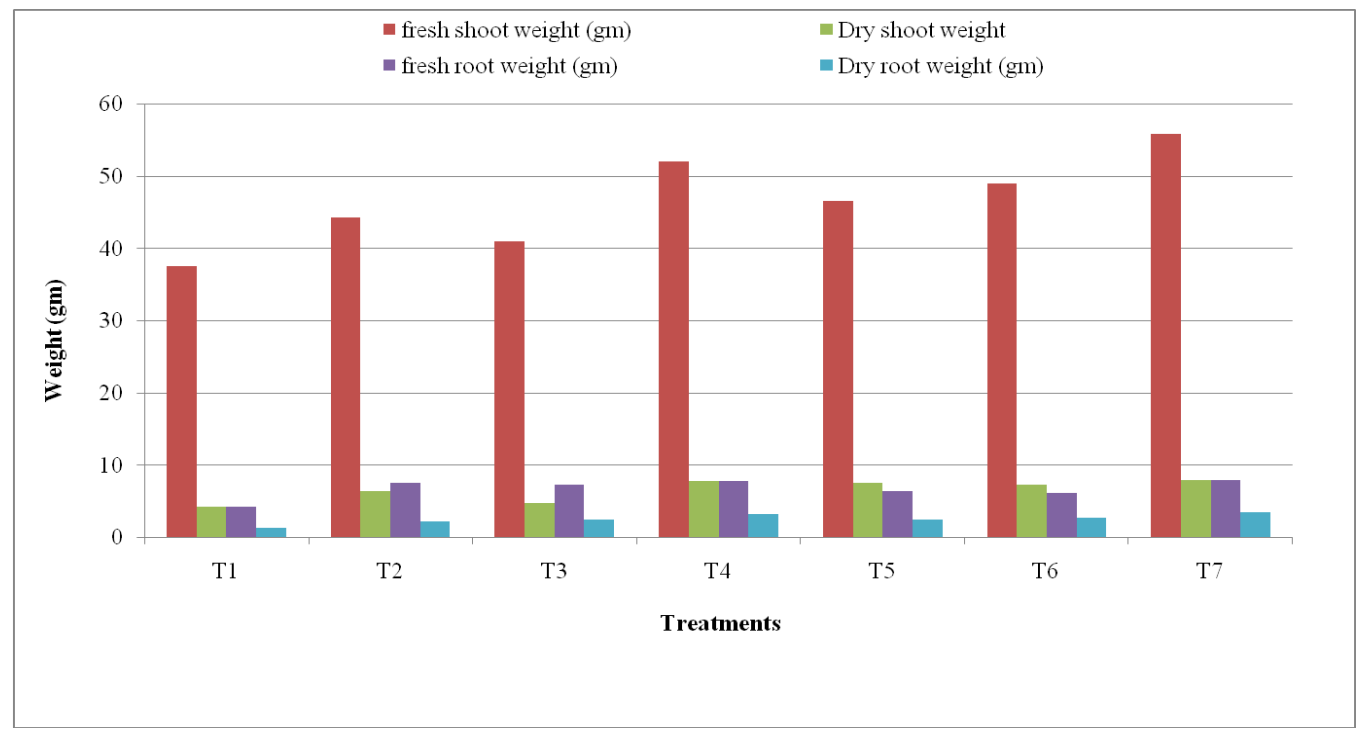

Fig.7 Effect of different treatments on nematode multiplication on okra infected by $M$. incognita

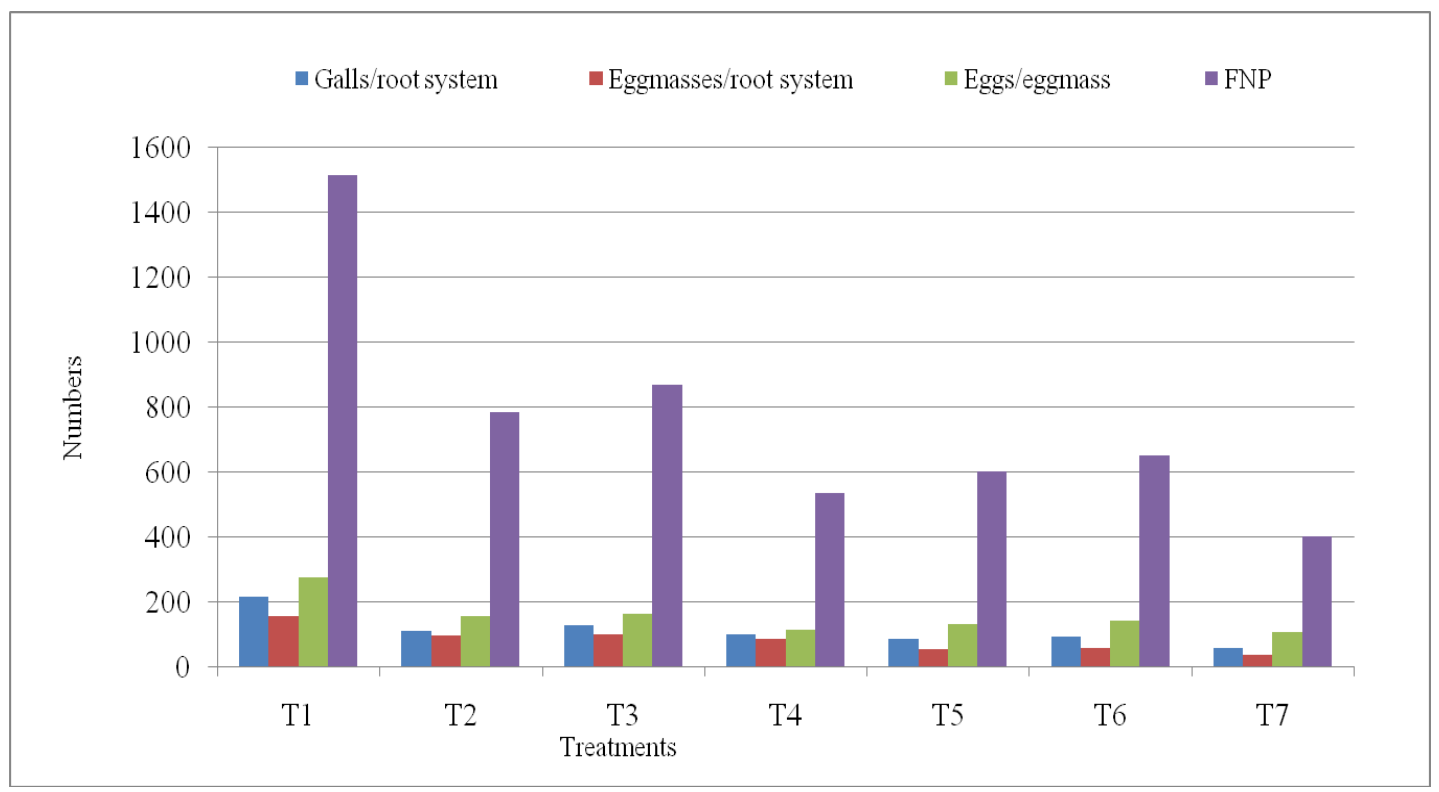

Data on the number of galls per root system, egg masses per root system, eggs per egg mass and final nematode population in the soil (Table 2, Fig. 7) recorded in all the treatments significantly differed from that of control. The treatments $\mathrm{T}_{7}$ i.e. seed treatment with Carbosulfan 25STD @ 3\% + soil application of Carbofuran@ @ $1 \mathrm{~kg}$ a.i/ha was found to be best in reducing the nematode multiplication followed by $\mathrm{T} 4$ i.e. seed

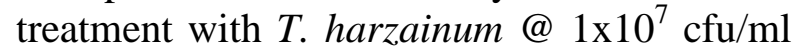
+ soil application of T. harzainum @ 1 $\times 10^{7}$ $\mathrm{cfu} / \mathrm{gm}$ at $5 \mathrm{~g} / \mathrm{kg}$ of soil. The results indicated that chemicals and bioagent when applied as a seed treatments and soil application were found to be significantly superior to those 
when they were applied either as a seed treatment or soil application in reducing galls in roots. Sundaram and Hangaraj (2001) also reported a reduction of the population of $M$. incognita, when $T$. harzianum were applied as a seed treatment. The fungal bioagent $T$. harzianum showed their bioefficacy against $M$. incognita in respect of reducing their reproduction rate as compared to the untreated control (Khan and Haque, 2011 T). Similarly, Lal and Rana (2013) who recorded the lowest number of galls, egg masses and final nematode population of $M$. incognita in okra plants treated with $T$. harzainum as a seed treatment and/or soil application thus confirmed the results of the present investigation.

The possible mechanism involved in Trichoderma antagonist against root-knot nematode had been studied extensively by Sharon et al., (2001). They reported two mechanisms (i) Trichoderma produced metabolites with an antinematode activity that immobilized $\mathbf{J}_{2}$ thus reduced root penetration and (ii) direct parasitism by the antagonist. The decrease in nematode root galls and nematode population by Trichoderma spp. has been reported by several workers (Tripathi et al., 2003, Kalita et al., 2012, Annapurna et al., 2018). The results of the present study also recorded that isolated $T$. harzainum parasitized to the egg and juvenile of $M$. incognita, as a result, reduced the nematode population when applied as a soil application and seed treatment on okra infected by $M$. incognita. Thus, the use of biocontrol agent' i.e. T. harzainum may be an effective alternative to the chemicals when applied together as a seed treatment and soil application showed significantly better results in an improving the plant growth parameters and reduction in the nematode multiplication as compared to the treatments with carbosulfan as a seed treatment and carbofuran as soil application alone for the management of $M$. incognita infected on okra under Assam condition..

\section{Acknowledgement}

The author is greatly thankful to Department of Plant Pathology, Assam Agricultural University, Jorhat, Assam for the identification of T. harzainum.

\section{References}

Annapurna, M., Bhagawati, B., and Kurulkar U. 2018. Biochemical mechanism of native fungal bioagents in the management of root-knot nematode Meloidogyne incognita on tomato. International Journal of Current Microbiology and Applied Science. 7(11): 380-395.

Anonymous. (2011). Three decades of nematology in Assam. AICRP on Plant parasitic nematodes with integrated approach for their control, Jorhat, Assam. pp-10.

Brotman, Y. et al., 2013. Trichoderma-plant root colonization: escaping early plant defense responses and activation of the antioxidant machinery for saline stress tolerance. PLoS Pathog., 9.

Chet, I., Inbar, J., and Hadar, Y. 1997. Fungal antagonists and mycoparasitism. In D. T. Wicklow \& B. So"derstro"m (Eds.), The mycota. Volume IV: Environmental and microbial relationships (pp. 165-184). Berlin, Heidelberg: Springer-Verlag.

Cofrancesco, A.F. 2000. Factors to consider when using native biological control organisms to manage exotic plants. Journal of Aquatic Plant Management. 38: 117-120.

Davis, E.L., Hussey, R.S and Baum, T.J. 2004.Getting to the roots of parasitism by nematodes. Trends Parasitol. 20, 134141.

Gams, W. and Bissett, J. 2002. Morphology and identification of Trichoderma. In: Kubicek, C.P. and Harman, G.E. (eds.). Trichoderma and Gliocladium: Basic 
biology, taxonomy and genetics. Taylor \& Francis Ltd, pp. 3-31.

Harman, G.E., Howell, C.R., Viterbo, A., Chet, I., and Lorito, M. 2004. Trichoderma spp.-opportunistic avirulent plant symbionts. Nature Microbiology Reviews, $2,43-56$.

Hermosa, R., Viterbo, A., Chet, I and Monte, E. 2012. Plant-beneficial effects of Trichoderma and of its genes. Microbiology. 158: 17-25.

Hussey, R.S and Janssen, P.1988. Immunogold localization of collagen in the cuticle of different life stages of Meloidogyne incognita. Journal of Nematology. 20: 641-642.

Jansson H-B, Nordbring-Hertz B. 1988. Infection events in the fungus-nematode system. In: Poinar GO Jr, Jansson H-B, eds. Diseases of nematodes. Boca Raton, FL, USA: CRC Press, 59-72.

Kalita, D.J., Bhagawati, B. and Gogoi, B. B. 2012. In-vitro efficacy of Trichoderma spp. against Meloidogyne incognita and Rhizoctonia solani. Indian Journal of Nematology. 42 (1):84-87.

Kerry, B.R. 2000. Rhizosphere interactions and exploitation of microbial agents for the biological control of plant parasitic nematodes. Annual Review of Phytopathology. 38: 423-441.

Khan, A., Williams, K.L and Nevalainen, H.K.M. 2004. Effects of Pacecilimyces lilacinus protease and chitinase on the eggshell structures and hatching of Meloidogyne javanica juveniles. Bio Control., 31: 346-35.

Khan, M.R., and Haque, Z. 2011. Soil application of Pseudomonas fluorescens and Trichoderma harzianum reduces rootknot nematode, Meloidogyne incognita, on tobacco. Phytopathologia Mediterranea. 50, 257-266.

Kok, C.J., papert, A., and Hok-A-Hin, C.H. 2001. Microflora of Meloidogyne egg masses: species composition, population density and effect on the biocontrol agent Verticillium chlamydosporium (Goddard). Nematology 3: 729-734.
Lal, B and Rana, B.P. 2013. Evaluation of fungi as seed and soil treatment against root knot nematode, Meloidogyne incognita in okra. Agricultural Science Digest. 33 (3): 226 - 229.

Lysek, H. (1963). Effect of certain soil organisms on the eggs of parasitic roundwonns. Nature.1(99): 925.

Lysek, H. (1966). Study of biology of feohelminths II. The importance of some soil microorganism for the variability of feohelminth eggs in the soil. Acta. Univ.Palacki, Oloumc. Fac. Rerum Nat. Biol. 40: 83-90.

Mankau, R. (1962). Soil fungistasis and nematophagous fungi. Phytopathology. 52, 611-615.

Mark, A.J., Christopher, AD., and Stefan, T.J. 2010. Ecological considerations in producing and formulating fungal entomopathogens for use in insect biocontrol. BioControl. 55: 129-145.

Morton, C.O., Hirsch, P.R., and Kerry, B. (2004). Infection of plant-parasitic nematodes by nematophagous fungi- $\mathrm{a}$ review of application of molecular biology to understand infection processes and to improve biological control. Nematology. 6: $161-170$.

Naserinasab, F., Sahebani, N., and Etebarian, H.R (2012). Biological control of Meloidogyne javanica by Trichoderma harzianum BI and salicylic acid on Tomato. African Journal of Food Science and Technology.5(3): $276-280$.

Pau, C.G., Leong, C.T.S., Wong, S.K., Eng, L., Jiwan, M., Kundat, F.R., Aziz, Z.F.B.A., Ahmed, O.H., and Majid, N.M. 2012. Isolation of indigenous strains of Paecilomyces lilacinus with antagonistic activity against Meloidogyne incognita. International Journal of Agriculture and Biological Sciences. 14: 197-203.

Rifai, M.A. (1969). A revision of the genus Trichoderma. Mycological Papers. 116: 1-56.

Saifullah, and Thomas, B.J. (1996). Studies on the parasitism of Globodera rostochiensis by Trichoderma harzianum using low 
temperature scanning electron microscopy. Afro-Asian Journal of Nematology. 6:117-122

Sharon, E., and Spiegel, Y. (1993). Glycoprotein characterization of the gelatinous matrix in the root-knot nematode Meloidogyne javanica. Journal of Nematology. 25: 585-589.

Sharon, E., Bar-Eyal, M., Chet, I., HerreraEstrella, A., Kleifeld, O., and Spiegel, Y. (2001). Biological control of the root-knot nematode Meloidogyne javanica by Trichoderma harzianum. Phytopathology. 91: 687-693.

Sharon, E., Chet, I., Viterbo, A., Bar-Eyal, M., Nagan, H., Samuels, G. J., and Spiegel, Y. ( 2007). Parasitism of Trichoderma on Meloidogyne javanica and role of the gelatinous matrix. European Journal of Plant Pathology.118: 247-258.

Shoresh, M., Harman, G.E., and Mastouri, F. (2010). Induced systemic resistance and plant responses to fungal biocontrol agents. Annual Review of Phytopathology. 48: 21-43.

Singh, S., and Mathur, N. (2010). In vitro studies of antagonistic fungi against the root-knot nematode, Meloidogyne incognita. Biocontrol Science and Technology. 20(3): 275-282.

Sundaram, R., and Thangaraj, T. (2001).Biointensive management of Meloidogyne incognita and Pythium aphanidurmatum in tomato nurseries. National Congress on Centary of Nematology in India:
Appraisal and future plans, Dec.5-7, IARI, New Delhi, p.169-170.

Szabó M., Csepregi K., Gálber M., Virányi F., and Fekete C. 2012. Control plantparasitic nematodes with Trichoderma species and nematode-trapping fungi: The role of chi18-5 and chi18-12 genes in nematode egg-parasitism. Biological Control. 63, 121-128.

Tikhonov, V.E., Lopez-Llorca, L.V., Salinas, J., and Jansson, H.B. (2002). Purification and characterization of chitinases from the nematophagous fungi Verticillium chlamydosporium and V. suchlasporium. Fungal Genetics and Biology. 35: 67-78.

Tripathi, P.K., Singh, C.S., Prasad, D., and Singh, O.P. (2006). Use of fungal bio agents for the management of Meloidogyne incognita infecting tomato. Annals of Plant Protection Sciences. 14: 194-196.

Yao, Yu-Rong., Tian, Xue-Liang., Shen, BaoMing., Mao, Zhen-Chuan., Chen, Guo-hua and Xie., and Bing-Yan. (2015). Transformation of the endophytic fungus Acremonium implicatum with GFP and evaluation of its biocontrol effect against Meloidogyne incognita. World Journal of Microbiology \& Biotechnology. 31: 549556.

Zhang, K.Q., and Hyde, K.D. 2014. NematodeTrapping Fungi. Dordrecht, Neth.: Springer.

\section{How to cite this article:}

Kurulkar Uday, Bhabesh Bhagawati and Pranjal Pratim Neog. 2019. Biological Control of Meloidogyne incognita by Trichoderma harzianum. Int.J.Curr.Microbiol.App.Sci. 8(02): 21762188. doi: https://doi.org/10.20546/ijcmas.2019.802.252 